\title{
Observations following discontinuation of long-term denosumab therapy
}

\author{
M. R. McClung ${ }^{1,2}$ • R. B. Wagman ${ }^{3}$ - P. D. Miller ${ }^{4}$ A. Wang $^{3}$ - E. M. Lewiecki ${ }^{5}$
}

Received: 2 October 2016 / Accepted: 9 January 2017 /Published online: 31 January 2017

(C) The Author(s) 2017. This article is published with open access at Springerlink.com

\begin{abstract}
Summary Stopping denosumab after 8 years of continued treatment was associated with bone loss during a 1-year observation study in patients who were not prescribed osteoporosis treatment. Bone loss was attenuated in patients who began another osteoporosis therapy. Treatment to prevent bone loss upon stopping denosumab should be considered.
\end{abstract}

Prior presentation This work was presented in part as an abstract and oral at ENDO 2013.

Electronic supplementary material The online version of this article (doi:10.1007/s00198-017-3919-1) contains supplementary material, which is available to authorized users.

M. R. McClung

mmcclung.ooc@gmail.com

R. B. Wagman

rwagman@amgen.com

P. D. Miller

MillerCCBR@aol.com

A. Wang

awang@amgen.com

E. M. Lewiecki

mlewiecki@gmail.com

1 Oregon Osteoporosis Center, 2881 NW Cumberland Road, Portland, OR 97210, USA

2 Australian Catholic University, Melbourne, Australia

3 Amgen Inc., Thousand Oaks, CA, USA

4 Colorado Center for Bone Research, Lakewood, CO, USA

5 New Mexico Clinical Research \& Osteoporosis Center, Albuquerque, NM, USA
Introduction This study aimed to understand osteoporosis management strategies during a 1-year observational follow-up after up to 8 years of denosumab treatment in a phase 2 study.

Methods During the observational year, patients received osteoporosis management at the discretion of their physician and returned to the clinic for BMD assessment and completion of an osteoporosis management questionnaire. Incidence of serious adverse events and fractures was collected. Analyses were descriptive.

Results Of 138 eligible patients, 82 enrolled in and completed the observation study. Most (65 [79\%]) did not receive prescription osteoporosis medication, with "my doctor felt I no longer needed a medication" being the most common reason (23 [35\%]). Of the 17 patients who took osteoporosis medications, 8 discontinued therapy during the observation study. In patients treated with denosumab for 8 years $(N=52)$, BMD decreased during the 1-year observation study (6.7\% [lumbar spine], $6.6 \%$ [total hip]). Those who took osteoporosis medication during the observation study showed a smaller decline in BMD than those who did not. No new safety concerns were identified. Eight patients $(9.8 \%)$, all of whom had at least one predisposing risk factor, experienced 17 fractures. This included seven patients who experienced one or more vertebral fractures.

Conclusions Consistent with denosumab's mechanism of action, treatment cessation led to reversal of the drug's effect on BMD and perhaps fracture risk. For patients who took osteoporosis therapy, bone loss was attenuated. For patients at high fracture risk, switching to another osteoporosis therapy if denosumab is discontinued seems appropriate.

Keywords Denosumab · Discontinuation · Osteoporosis · Treatment cessation 


\section{Introduction}

Osteoporosis is a chronic disorder that requires long-term treatment with pharmacologic therapy to ensure sustained antifracture benefit. Due to concerns about rare bone safety events, including atypical femoral fracture (AFF) and osteonecrosis of the jaw (ONJ), questions have arisen regarding appropriate duration of treatment and whether efficacy, safety, and/or time-dependent thresholds should dictate when to discontinue therapy $[1,2]$. Bisphosphonates have a long terminal half-life in bone due to affinity to hydroxyapatite, and they are not metabolized. This has prompted the thinking that stopping therapy for an interval of time, commonly referred to as a "drug holiday," could save medical costs while maintaining treatment benefits for at least some time, particularly in patients no longer at high risk of fracture [3, 4]. Because of differences in mechanisms of action and metabolic clearance among different drug classes, the concept of a bisphosphonate drug holiday is not applicable to reversible, non-bisphosphonate treatments, including estrogen therapy, estrogen agonists/antagonists (raloxifene, bazedoxifene), parathyroid hormone analogues (teriparatide, abaloparatide), and the RANKL inhibitor denosumab. However, there are only limited data showing that treatment cessation with non-bisphosphonate bone active therapies may not be appropriate [5-10].

Denosumab, a therapy for osteoporosis in men and postmenopausal women and for bone loss associated with hormone ablation therapy, is a fully human monoclonal antibody that binds to and inhibits RANKL. Treatment for up to 10 years results in continued gains in lumbar spine and total hip bone mineral density (BMD) without therapeutic plateau, with low fracture incidence, and a safety profile that remained consistent over time [11-15]. Rare cases of femoral fractures with atypical features $(N=2)$ and osteonecrosis of the jaw $(n=$ 8 ) have been observed with denosumab therapy up to 8 years [14]. The original 4-year denosumab phase 2 dose-ranging trial was extended to 8 years to understand long-term effects of continued therapy [16-20]. An additional 1-year observation study following the end of treatment was conducted to understand osteoporosis management strategies chosen by clinicians for patients with low bone mass who had received denosumab for up to 8 years. This report summarizes data from this final year.

\section{Methods}

The methodologies of both the original phase 2 dose-ranging parent study (years 1-4) and its extension (years 5-8) have already been published [16-20]. Details of the 1-year observation study (year 9) following the end of 8 years of denosumab treatment are described below.

\section{Study design}

Postmenopausal women who successfully completed the 8 years of the parent and extension study were eligible to participate in the observation study. There were no studyspecific medications or supplements administered during the 1-year observation. However, any medication or supplements could be prescribed at the discretion of the patients' health care providers.

Patients were asked to return to the clinic at the end of the observation study to provide information about osteoporosis medication management, including incidence, type, and reason for initiating and stopping prescription osteoporosis drug use since completing the extension study at the end of year 8 (Supplemental Table 1), and for BMD assessments. Mean percentage changes in lumbar spine and total hip BMD during the observation study were stratified by osteoporosis medication status. Serious adverse events were recorded, as were clinical fractures that occurred since the end of treatment at year 8 . During the phase 2 dose-ranging trial, its extension, and the observation study, spinal radiographs were not routinely obtained but only at the discretion of the treating clinician. A formal statistical hypothesis was not tested at the end of this 1-year observation study. All analyses were descriptive in nature.

The study protocol was reviewed and approved by an institutional review board at each center, and all women provided written informed consent. The study was performed in compliance with the Food and Drug Administration, International Conference on Harmonisation Good Clinical Practice guidelines, and the World Medical Association Declaration of Helsinki principles.

\section{Results}

\section{Patient disposition}

Of the 200 patients enrolled in the extension study of the phase 2 dose-ranging trial, 138 patients completed the 4-year extension. Eight-two of those patients, from 13 centers in the USA, enrolled in the observation study (Fig. 1), all of whom completed the 1-year study.

\section{Baseline characteristics}

Patients enrolled in the observation study were women with a mean age of 68.9 years ( $22 \%$ were $\geq 75$ years of age) who had been postmenopausal for an average of approximately 18 years (Table 1 ). The majority of the patients were Caucasian (89\%); 6.1\% were Hispanic. Mean BMD T-scores at the lumbar spine and total hip were -1.08 and -1.03 , respectively, while the average T-scores had been -2.14 and 
Fig. 1 Design of the parent study, its extension, and the observation study. $D M A b$ denosumab, $Q 3 M$ once every 3 months, $Q 6 M$ once every 6 months, $Q W$ once weekly

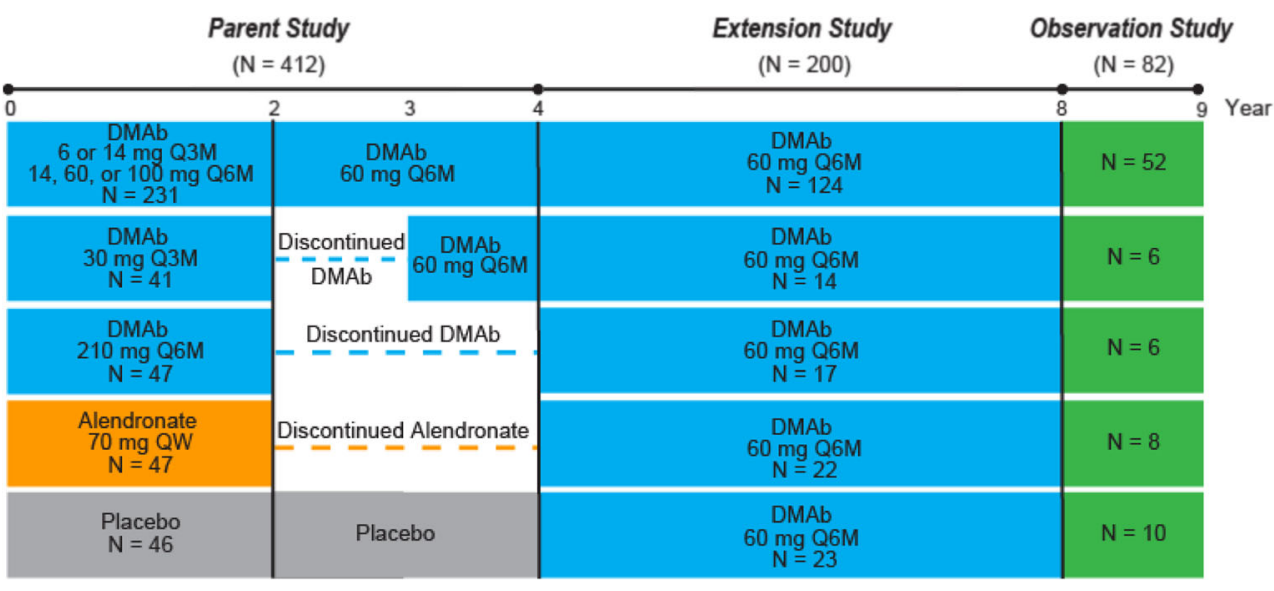

-1.44 , respectively, 8 years earlier at the beginning of the phase 2 study.

\section{Osteoporosis medication management}

The majority of the 82 patients (65 [79\%]) reported that they did not take prescription medication for osteoporosis during the observation study. Of these patients, 34 (52\%) reported that their physician had recommended no treatment, with the most common reason being that the doctor felt that the patient no longer needed a medication (Supplemental Fig. 1). Most of the $17(21 \%)$ patients who did take prescription medication for osteoporosis did so on the recommendation of either the research physician for this study $(n=7)$ or their personal physician $(n=6)$. The following medications were taken by patients for osteoporosis management: alendronate (seven patients), denosumab (five patients), risedronate (four patients), ibandronate (two patients), and teriparatide (two patients) (Supplemental Fig. 1). Three patients switched osteoporosis medications during the observational period: one from alendronate to risedronate due to gastrointestinal $\mathrm{AE}$ and then discontinued due to medication cost, one from alendronate to ibandronate due to unspecified $\mathrm{AE}$, and one from ibandronate 17 patients stopped taking their osteoporosis medication during the observation study, with most $(n=5)$ noting side effects of the medication as the reason. Nine of the 17 patients were still taking an osteoporosis medication at the end of the 1-year observation. Daily supplementation of 400-800 IU vitamin D and at least $500 \mathrm{mg}$ elemental calcium had been required throughout the treatment phase of the study, and all 82 patients continued to take both supplements during the observation study.

\section{Bone mineral density}

For patients who received denosumab for 8 years $(n=52)$ and those who received placebo for 4 years during the parent study followed by denosumab for 4 years in the extension study $(n=10)$, mean percentage change in BMD was assessed from phase 2 dose-ranging trial baseline to the end of the 8-year treatment phase of the extension study (years 1-8), to the end of the observational year (years 1-9), and from the end of the extension study to the end of the observational year (year 9). In the 10 patients who took denosumab during the extension study (years 5-8) after having received placebo during years to teriparatide without specified reason. Eight (47\%) of these

Table 1 Baseline characteristics

\begin{tabular}{|c|c|c|c|c|}
\hline & \multicolumn{2}{|l|}{ Parent study } & \multirow{2}{*}{$\begin{array}{l}\text { Extension study } \\
\text { Years 5-8 } \\
\text { Baseline }\end{array}$} & \multirow{2}{*}{$\begin{array}{l}\text { Observation study } \\
\text { Year } 9 \\
\text { Baseline }\end{array}$} \\
\hline & \multicolumn{2}{|l|}{$\begin{array}{l}\text { Years 1-4 } \\
\text { Baseline }\end{array}$} & & \\
\hline & $\begin{array}{l}\text { All patients } \\
N=412\end{array}$ & $\begin{array}{l}\text { Denosumab } \\
N=319\end{array}$ & $\begin{array}{l}\text { Denosumab } \\
N=200\end{array}$ & $\begin{array}{l}\text { All patients } \\
N=82\end{array}$ \\
\hline Age, years & $62.5(8.1)$ & $62.3(8.0)$ & $66.1(7.7)$ & $68.9(6.4)$ \\
\hline Age $\geq 75$ years, $n(\%)$ & $35(8.5)$ & $24(7.5)$ & $29(14.5)$ & $18(22.0)$ \\
\hline Lumbar spine T-score & $-2.14(0.78)$ & $-2.14(0.77)$ & $-1.55(0.96)$ & $-1.08(1.04)$ \\
\hline Total hip T-score & $-1.44(0.71)$ & $-1.42(0.69)$ & $-1.21(0.73)$ & $-1.03(0.77)$ \\
\hline Patients who completed, $n(\%)$ & $262(64)$ & $203(64)$ & $138(69)$ & $82(100)$ \\
\hline
\end{tabular}

Values are mean (standard deviation) unless indicated otherwise 
1-4, BMD decreased but remained above or near their predenosumab treatment values during the observation study (Fig. 2). The remainder of the discussion of BMD results focuses on the group that had received 8 years of denosumab treatment during the phase 2 dose-ranging trial and its extension because this is the largest cohort $(N=52)$ that was followed longitudinally and, therefore, has the least variability in BMD measurements. After treatment with denosumab for 8 years, the average increases in BMD at the lumbar spine and total hip were 16.8 and $6.2 \%$, respectively. During the observation study (year 9), BMD decreased, on average, by $6.7 \%$ at the lumbar spine and $6.6 \%$ at the total hip (Fig. 2). Over the full 9-year period, BMD remained above or near the phase 2 study baseline level at the lumbar spine $(+9.1 \%)$ and total hip $(-1.0 \%)$, respectively.

The changes in BMD during the year 9 observation study were influenced by osteoporosis medications. For patients who received denosumab for 8 years during the phase 2 study and who did not take any prescription medications for osteoporosis during the observation study $(N=42)$, mean BMD change over the 1-year observation was $-7.4 \%$ at the lumbar spine and $-7.8 \%$ at the total hip (Fig. 3). Compared with their values at the phase 2 parent trial baseline, the BMD over the 9year study period remained above or near level at the lumbar spine $(+8.2 \%)$ and total hip $(-2.2 \%)$, respectively. In contrast, among the five patients who were taking prescription medications for osteoporosis at the end of the observation study, the mean BMD change over the observation study was $-2.9 \%$ at the lumbar spine and $-2.2 \%$ at the total hip (Fig. 3). Decreases in BMD during year 9 in five patients who took osteoporosis medications for only part of that year were intermediate $(-4.4 \%$ at lumbar spine and $-6.1 \%$ at total hip) between those who took medication throughout the year and those who did not.

\section{Adverse events}

During the observation study, a total of nine serious adverse events were reported in 8 of 82 patients (9.8\%; Table 2). No serious adverse event was reported in more than one patient.
Fig. 2 Percentage change from phase 2 dose-ranging trial baseline for a lumbar spine and $\mathbf{b}$ total hip bone mineral density $(B M D)$. Includes patients who enrolled into the observation study with 8 years of denosumab $(D M A b)$ treatment $(N=52)$ or those with 4 years of placebo followed by 4 years of DMAb treatment $(N=10) . n=$ number of subjects with observed BMD at baseline and year 9. $C I$ confidence interval, $L S M$ least squares mean
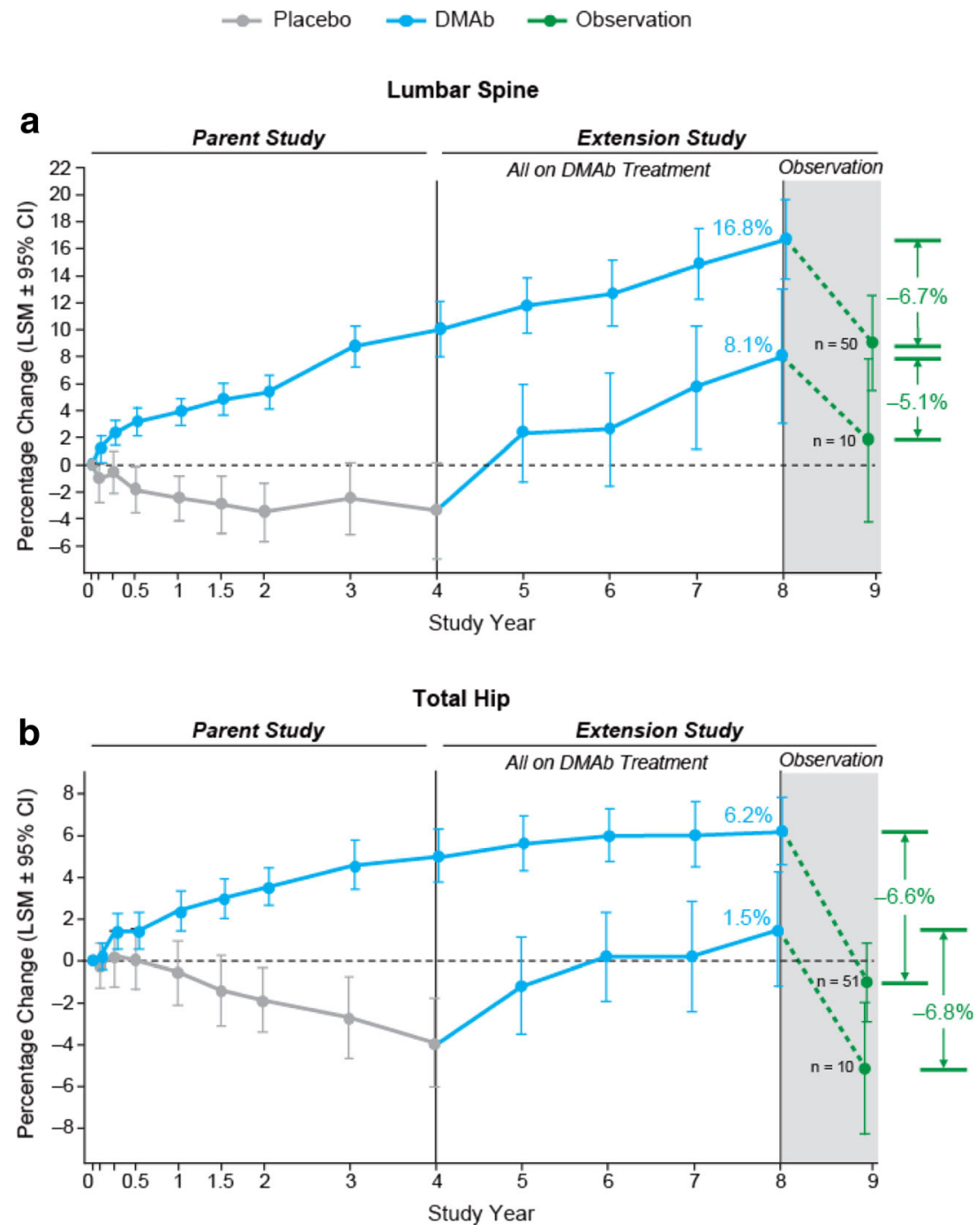


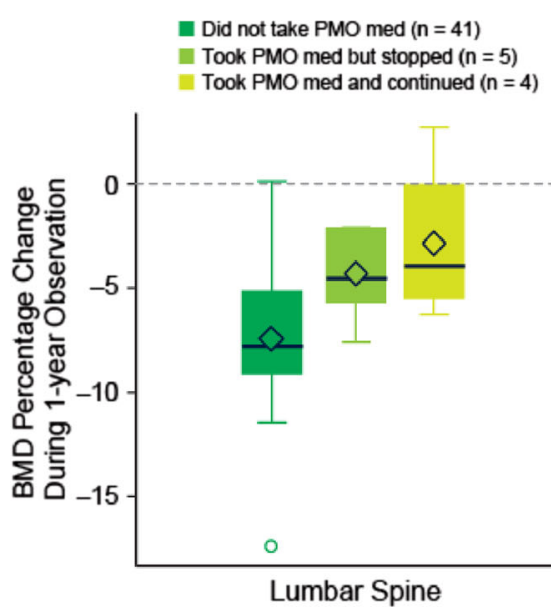

Fig. 3 Percentage change from observation study baseline in bone mineral density $(B M D)$ during the 1-year observation study stratified by postmenopausal osteoporosis $(P M O)$ medication $(m e d)$ status. Data are from 52 patients who enrolled into the observation study after 8 years of

These serious adverse events occurred in one patient each: aortic stenosis, breast cancer in situ, femoral neck fracture, lobar pneumonia, non-cardiac chest pain, osteoarthritis, and benign pituitary tumor. Two serious adverse events (asthenia and balance disorder) were reported in one patient. No deaths or withdrawal of patients due to serious adverse events were reported. There were no serious adverse events of interest regarding hypocalcemia, ONJ, eczema, skin infection, hypersensitivity, acute pancreatitis, delayed fracture healing, or atypical femoral fractures.

During the observation study, 8 of $82(9.8 \%)$ patients experienced at least one fracture (Table 2); a total of 17 fractures were reported. Four patients had multiple vertebral fractures, including one with a subsequent femoral neck fracture, three patients had a single vertebral fracture, and one patient had a radius fracture (Table 3). Since

Table 2 Adverse events during the 1-year observation study

\begin{tabular}{ll}
\hline & $\begin{array}{l}\text { Number of patients }(\%) \\
\text { Total patients }=82\end{array}$ \\
\hline Serious adverse events $^{\text {Infections }}{ }^{\mathrm{a}}$ & $8(9.8)$ \\
Malignant neoplasms $^{\mathrm{b}}$ & $1(1.2)$ \\
Fractures $^{\text {Vertebral }}$ & $1(1.2)$ \\
Femoral neck & $8(9.8)$ \\
Radius & $7(7.3)$ \\
Deaths & $1(1.2)$ \\
\hline
\end{tabular}

Data are $n(\%)$. No patients were reported to have a serious adverse event of skin infection, eczema, hypocalcemia, hypersensitivity, pancreatitis, adjudicated positive osteonecrosis of the jaw, atypical femoral fracture, or delayed fracture healing

${ }^{\text {a }}$ Infection was a lobar pneumonia

${ }^{\mathrm{b}}$ Malignant neoplasm was a breast cancer in situ
Did not take PMO med $(n=40)$

Took PMO med but stopped $(\mathrm{n}=5)$

Took PMO med and continued $(n=5)$

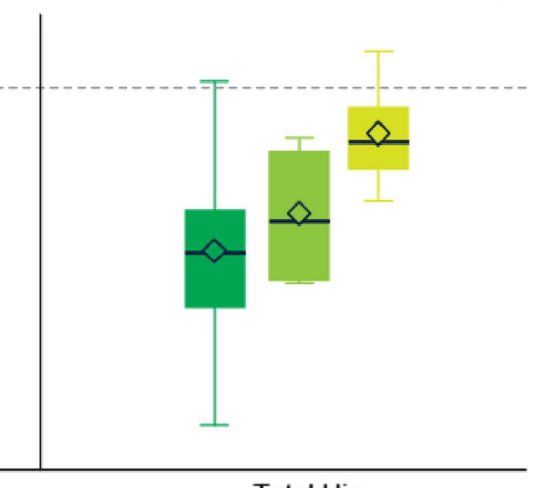

Total Hip

continued denosumab treatment. $n=$ number of subjects with observed BMD at year 8 and year 9. In each box-and-whisker plot, the box represents the 25th and 75th percentiles, the middle line represents the median, and the diamond represents the mean

spine radiographs were not obtained during the 8-year phase 2 trial, it was difficult to know whether the vertebral fractures noted on radiographs during the observation study were acute or chronic. Of the eight patients who fractured, six did not take any prescription medication for osteoporosis during the observation study; the other two patients began an osteoporosis medication only after the fracture event. We also are aware of reported vertebral fracture events after stopping denosumab therapy in two additional patients who participated in the treatment and extension components of the phase 2 study but declined to enroll in the observation study. These two cases are also included in Table 3.

\section{Discussion}

After completing the phase 2 clinical trial during which patients had received up to 8 years of denosumab treatment, most patients did not receive any medication for osteoporosis during the 1-year observation period. Most often, the patient's physician had recommended that medication was no longer required. As is often the case, about half of the patients who began a prescription medication for osteoporosis after denosumab discontinuation stopped the therapy during the 1-year follow-up.

The decision by the patient and her personal physician not to continue therapy may have seemed reasonable since BMD on denosumab therapy had increased substantially, to average values well above the indications for treatment. However, unlike the skeletal effects of bisphosphonates which dissipate slowly, BMD decreases more quickly upon stopping more rapidly reversible agents such as estrogen, denosumab, and odanacatib [18, 21-24]. Consistent with that knowledge, 


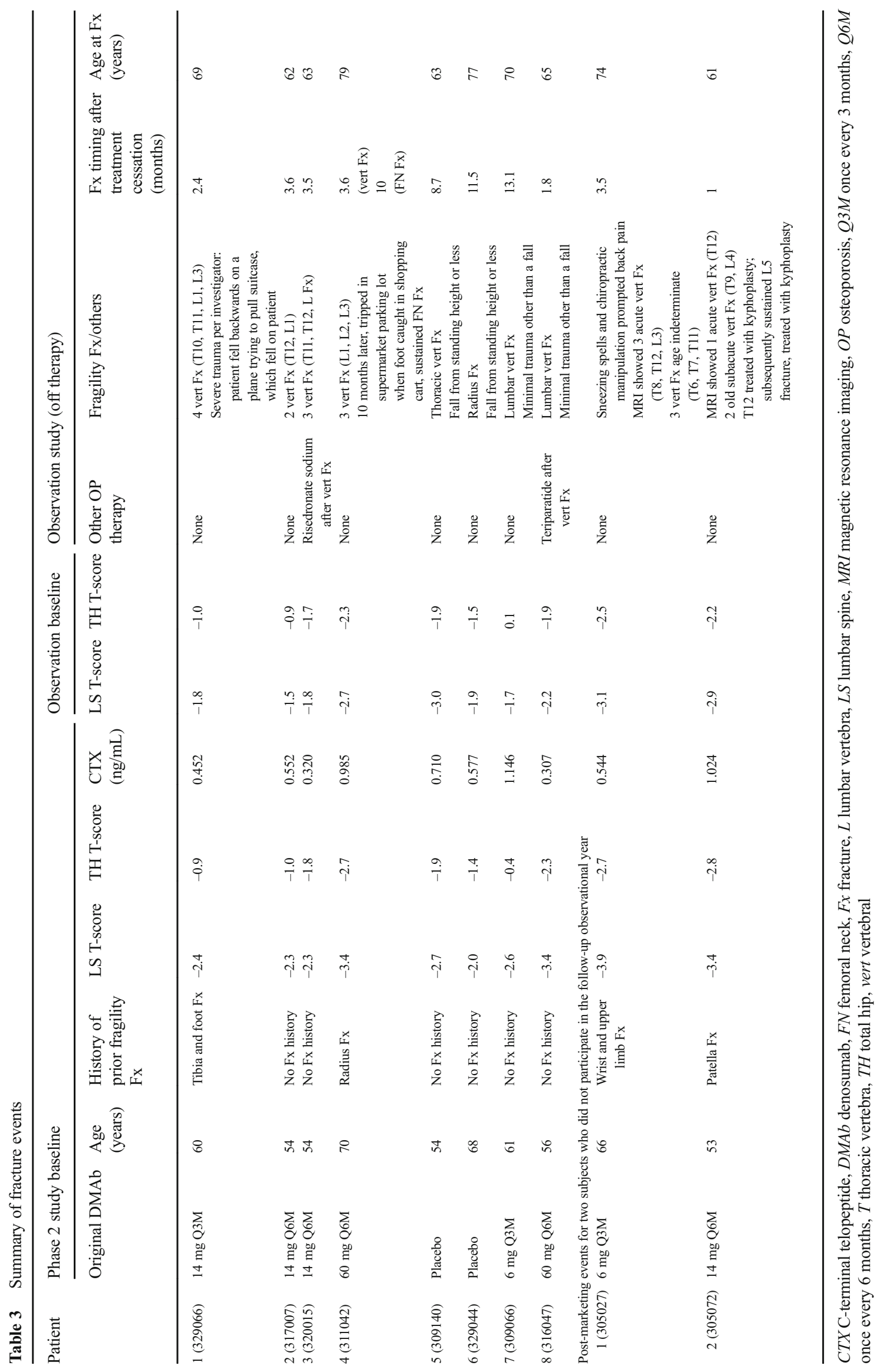


BMD decreased in our patients who stopped denosumab therapy and who did not take other osteoporosis medication. The rate of bone loss observed in those patients (6-7\% in a year) was similar to that seen in earlier studies, although our patients had received therapy much longer. This suggests that longterm denosumab therapy, although resulting in large gains in $\mathrm{BMD}$, does not protect patients from bone loss when therapy is discontinued. However, because the patients had experienced such large increases in BMD during the phase 2 trial, the lumbar spine BMD remained well above the phase 2 trial baseline 1 year after discontinuation, while the total hip BMD fell back to the average baseline value.

Taking an osteoporosis medication after stopping denosumab appeared to attenuate this decline in BMD. This is consistent with the observation that alendronate prevents bone loss upon stopping estrogen, parathyroid hormone, or denosumab therapy [25-27]. In the latter study, postmenopausal women with low bone mass who had received denosumab for 1 year were switched to weekly alendronate therapy. The increase in BMD that had occurred with denosumab therapy was preserved during 1 year of alendronate therapy.

Eight of the 82 patients $(9.8 \%)$ experienced one or more osteoporotic fractures during the 1-year observation study after stopping denosumab therapy. The incidence of osteoporotic fracture was $4.9 \%$ in patients who were receiving denosumab during years 5-8 of the phase 2 study [20]. All patients in the observation study who experienced a fracture had at least one predisposing risk factor for fracture (e.g., prior fragility fracture, low BMD, advanced age). None of the patients with fractures had received osteoporosis treatment after stopping denosumab before their fractures occurred.

There is theoretical concern about a possible increased risk of fracture upon stopping estrogen or denosumab due to the rebound in bone turnover to values above pretreatment levels and the accompanying interval of rapid bone loss [18, 28]. This concern is based on evidence that high bone turnover is a risk factor for fracture [29]. Protection from fragility fractures appears to persist for at least several months after stopping teriparatide therapy $[9,10]$. However, in that setting, bone turnover decreases upon stopping therapy, in contrast to the large increase in turnover upon stopping estrogen or denosumab. Observational studies suggest that fracture risk increases upon stopping estrogen therapy, but whether there is an increase in risk above that seen in untreated women cannot be determined in those studies [5-7]. A careful analysis of women in the Women's Health Initiative (WHI) study demonstrated that hip and vertebral fracture risk after stopping estrogen therapy quickly returned to but did not rise above that observed in the group that had received placebo [8].

Fracture incidence after denosumab therapy cessation has been evaluated in five clinical trials: an earlier part of this phase 2 dose-ranging study in postmenopausal women with low bone mass [18], pivotal phase 3 fracture trial in postmenopausal women with osteoporosis (Fracture Reduction Evaluation of Denosumab in Osteoporosis Every 6 Months [FREEDOM] Study [30]), phase 3 BMD study in postmenopausal women with low bone mass [23], phase 3 prostate cancer study (Hormone Ablation Therapy [HALT] Study [31]), and phase 3 breast cancer study (HALT; [data on file]). While these 5 studies in 2671 patients do not demonstrate an excess in fracture risk after discontinuation of denosumab, only the patients in the FREEDOM study had osteoporosis prior to treatment. In that study by Brown and colleagues [30], the average duration of denosumab therapy was 3.4 doses (less than 2 years), and the median follow-up after stopping therapy was 0.8 years (maximum 24 months). In the 327 women who had discontinued denosumab, the incidence of both vertebral fracture and osteoporotic fracture was lower than that in the 470 women who had discontinued placebo therapy.

Multiple or severe vertebral fractures occurring soon after stopping denosumab therapy have recently been described in five patients, four of whom had osteoporosis before treatment, who had received five to six doses of denosumab [32-34]. Like those patients, most of the vertebral fractures noted during the year of our observation study occurred within 3 to 4 months of treatment cessation, that is, 9 to 10 months after receiving their last dose of denosumab. The incidence of clinical vertebral fractures in our study (7/84 or $8 \%$ in 12 months) appears to be higher than was observed in women discontinuing estrogen therapy in the Women's Health Initiative (WHI) study $(<0.5 \%)$ [8]. The women in our study were enrolled on the basis of low bone mass, which was not the case in the WHI. All of our patients who experienced vertebral fractures had a lumbar spine BMD T-score of -2.3 or lower at the beginning of the phase 2 study. Moreover, four of the seven patients in the observation study who experienced vertebral fracture, as well as both of the patients who were not in the observational study but who were known to have had a vertebral fracture after stopping denosumab, had a lumbar spine BMD T-score less than -2.5 at the phase 2 study baseline. Thus, it is possible that women in our study who had osteoporosis and the associated disruption of trabecular microarchitecture are more susceptible to vertebral fracture if high bone remodeling and rapid bone loss occurs upon stopping therapy than were patients in the WHI study who were generally younger, had higher bone density, and, probably, better trabecular structure.

Few studies have explored long-term management strategies in osteoporosis. This study is the first that involves a reversible treatment for osteoporosis. The emergence of rare bone safety concerns-ONJ and AFF- has 
prompted the thought that these events may be related to long treatment duration with bisphosphonates and denosumab. In many regions, health authorities have updated product labeling for bisphosphonates to encourage assessment of benefit/risk after 3-5 years of treatment before consideration of continuing treatment. The implication (to date unproven) is that a proposed "drug holiday or treatment cessation" will reduce the risks of ONJ and AFF. These and other potential rare risks of osteoporosis medication should not deter clinicians from treating patients with osteoporosis with an increased fracture risk. Indeed, in appropriately selected patients, the risk of fragility fracture is far higher than risk of ONJ or AFF, with the benefits of treatment far outweighing the risks [35]. The results of this study make it clear that a "drug holiday" or "treatment cessation" is not appropriate for patients with osteoporosis who have been on long-term denosumab treatment.

We recognize that our study has many limitations, including its small size, observational design, the lack of spinal radiographs prior to and at the end of the study, and it not being planned to evaluate the effects of therapy on BMD or fracture risk during the observation study. The experience described here, however, reinforces our knowledge that, consistent with the drug's mechanism of action, treatment cessation after long-term therapy is associated with reversibility of the treatment effect, including protection from vertebral fracture. The finding of an increase in fracture risk after stopping denosumab therapy is not surprising and may be similar to the loss of fracture protection observed upon stopping estrogen therapy. Given the small number of patients in our study and the lack of a control group, the question of whether an interval of excess risk occurs in women with osteoporosis when denosumab therapy is stopped cannot be answered. Our results do add to the evidence that transitioning to another osteoporosis therapy attenuates bone loss upon stopping denosumab.

Osteoporosis is a chronic condition requiring long-term if not indefinite treatment, especially in high-risk patients. While denosumab therapy increases BMD and reduces fracture risk, the disruption of trabecular architecture caused by osteoporosis is not reversed with treatment. The suggestion of a loss of fracture protection, which appears as an increase in fracture frequency after stopping denosumab therapy, is not surprising given its reversible mechanism and may be similar to the loss of fracture protection observed upon stopping estrogen therapy [8]. There are few reasons to discontinue denosumab therapy. However, if denosumab treatment is discontinued for any reason, it seems very prudent that therapy with another antiremodeling agent, such as a long-acting bisphosphonate, should be continued in patients at high risk for fracture unless there is a compelling reason not to do so.
Acknowledgements The authors thank the trial investigators and participants. This study was funded by Amgen Inc. Michelle N Bradley, PhD provided medical writing support on behalf of Amgen Inc.

\section{Compliance with ethical standards}

Conflicts of interest MRM is a consultant for Amgen Inc., Merck, and Radius Health and receives honoraria from Amgen Inc. and Merck. RBW and AW are employees of and holders of stock and/or stock options in Amgen Inc. PDM receives research grants from Alexion, Eli Lilly, Amgen Inc., Novartis, National Bone Health Alliance, Pfizer, University of Alabama, Boehringer Ingelheim, Merck, Merck Serono, and Radius Health and is a consultant for Grunenthal, Shionogi, Radius Health, Amgen Inc., and Eli Lilly. EML receives research grants from Amgen Inc., Eli Lilly, and Merck and is a consultant for Amgen Inc., Eli Lilly, Merck, and Radius Health.

Financial support This study was sponsored by Amgen Inc., Thousand Oaks, CA, USA.

Open Access This article is distributed under the terms of the Creative Commons Attribution-NonCommercial 4.0 International License (http:// creativecommons.org/licenses/by-nc/4.0/), which permits any noncommercial use, distribution, and reproduction in any medium, provided you give appropriate credit to the original author(s) and the source, provide a link to the Creative Commons license, and indicate if changes were made.

\section{References}

1. Adler RA, El-Hajj Fuleihan G, Bauer DC, Camacho PM, Clarke BL, Clines GA, Compston JE, Drake MT, Edwards BJ, Favus MJ, Greenspan SL, McKinney RJ, Pignolo RJ, Sellmeyer DE (2016) Managing osteoporosis in patients on long-term bisphosphonate treatment: report of a task force of the American Society for Bone and Mineral Research. J Bone Miner Res 31:16-35

2. Whitaker M, Guo J, Kehoe T, Benson G (2012) Bisphosphonates for osteoporosis - where do we go from here? N Engl J Med 366:20482051

3. Diab DL, Watts NB (2014) Use of drug holidays in women taking bisphosphonates. Menopause 21:195-197

4. McClung M, Harris ST, Miller PD, Bauer DC, Davison KS, Dian L, Hanley DA, Kendler DL, Yuen CK, Lewiecki EM (2013) Bisphosphonate therapy for osteoporosis: benefits, risks, and drug holiday. Am J Med 126:13-20

5. Banks E, Beral V, Reeves G, Balkwill A, Barnes I, Million Women Study Collaborators (2004) Fracture incidence in relation to the pattern of use of hormone therapy in postmenopausal women. JAMA 291:2212-2220

6. Barrett-Connor E, Wehren LE, Siris ES, Miller P, Chen YT, Abbott TA, Berger ML, Santora AC, Sherwood LM (2003) Recency and duration of postmenopausal hormone therapy: effects on bone mineral density and fracture risk in the National Osteoporosis Risk Assessment (NORA) study. Menopause 10:412-419

7. Yates J, Barrett-Connor E, Barlas S, Chen YT, Miller PD, Siris ES (2004) Rapid loss of hip fracture protection after estrogen cessation: evidence from the National Osteoporosis Risk Assessment. Obstet Gynecol 103:440-446

8. Heiss G, Wallace R, Anderson GL, Aragaki A, Beresford SA, Brzyski R, Chlebowski RT, Gass M, LaCroix A, Manson JE, Prentice RL, Rossouw J, Stefanick ML, WHI Investigators (2008) Health risks and benefits 3 years after stopping randomized treatment with estrogen and progestin. JAMA 299:1036-1045 
9. Lindsay R, Scheele WH, Neer R, Pohl G, Adami S, Mautalen C, Reginster JY, Stepan JJ, Myers SL, Mitlak BH (2004) Sustained vertebral fracture risk reduction after withdrawal of teriparatide in postmenopausal women with osteoporosis. Arch Intern Med 164: 2024-2030

10. Prince R, Sipos A, Hossain A, Syversen U, Ish-Shalom S, Marcinowska E, Halse J, Lindsay R, Dalsky GP, Mitlak BH (2005) Sustained nonvertebral fragility fracture risk reduction after discontinuation of teriparatide treatment. J Bone Miner Res 20: $1507-1513$

11. Cummings SR, San Martin J, McClung MR, Siris ES, Eastell R, Reid IR, Delmas P, Zoog HB, Austin M, Wang A, Kutilek S, Adami S, Zanchetta J, Libanati C, Siddhanti S, Christiansen C, Freedom Trial (2009) Denosumab for prevention of fractures in postmenopausal women with osteoporosis. N Engl J Med 361:756-765

12. Papapoulos S, Chapurlat R, Libanati C, Brandi ML, Brown JP, Czerwiński E, Krieg MA, Man Z, Mellström D, Radominski SC, Reginster JY, Resch H, Román Ivorra JA, Roux C, Vittinghoff E, Austin M, Daizadeh N, Bradley MN, Grauer A, Cummings SR, Bone HG (2012) Five years of denosumab exposure in women with postmenopausal osteoporosis: results from the first two years of the FREEDOM extension. J Bone Miner Res 27:694-701

13. Bone HG, Chapurlat R, Brandi ML, Brown JP, Czerwinski E, Krieg MA, Mellstrom D, Radominski SC, Reginster JY, Resch H, Ivorra JA, Roux C, Vittinghoff E, Daizadeh NS, Wang A, Bradley MN, Franchimont N, Geller ML, Wagman RB, Cummings SR, Papapoulos S (2013) The effect of three or six years of denosumab exposure in women with postmenopausal osteoporosis: results from the FREEDOM extension. J Clin Endocrinol Metab 98:4483-4492

14. Papapoulos S, Lippuner K, Roux C, Lin CJ, Kendler DL, Lewiecki EM, Brandi ML, Czerwinski E, Franek E, Lakatos P, Mautalen C, Minisola S, Reginster JY, Jensen S, Daizadeh NS, Wang A, Gavin M, Libanati C, Wagman RB, Bone HG (2015) The effect of 8 or 5 years of denosumab treatment in postmenopausal women with osteoporosis: results from the FREEDOM Extension study. Osteoporos Int 26:2773-2783

15. Bone HG, Brandi ML, Brown JP, Chapurlat R, Cummings SR, Czerwinski E, Fahrleitner-Pammer A, Kendler DL, Lippuner K, Reginster JY, Roux C, Vittinghoff E, Daizadeh NS, Wang A, Dakin P, Wagman RB, Papapoulos S (2015) Ten years of denosumab treatment in postmenopausal women with osteoporosis: results from the FREEDOM Extension Trial. J Bone Miner Res (ASBMR Annual Meeting Abstracts) 30(Suppl 1):S471

16. McClung MR, Lewiecki EM, Cohen SB, Bolognese MA, Woodson GC, Moffett AH, Peacock M, Miller PD, Lederman SN, Chesnut CH, Lain D, Kivitz AJ, Holloway DL, Zhang C, Peterson MC, Bekker PJ, AMG 162 Bone Loss Study Group (2006) Denosumab in postmenopausal women with low bone mineral density. N Engl J Med 354:821831

17. Lewiecki EM, Miller PD, McClung MR, Cohen SB, Bolognese MA, Liu Y, Wang A, Siddhanti S, Fitzpatrick LA, AMG 162 Bone Loss Study Group (2007) Two-year treatment with denosumab (AMG 162 ) in a randomized phase 2 study of postmenopausal women with low BMD. J Bone Miner Res 22:1832-1841

18. Miller PD, Bolognese MA, Lewiecki EM, McClung MR, Ding B, Austin M, Liu Y, San Martin J, AMG 162 Bone Loss Study Group (2008) Effect of denosumab on bone density and turnover in postmenopausal women with low bone mass after long-term continued, discontinued, and restarting of therapy: a randomized blinded phase 2 clinical trial. Bone 43:222-229

19. Miller PD, Wagman RB, Peacock M, Lewiecki EM, Bolognese MA, Weinstein RL, Ding B, San Martin J, McClung MR (2011) Effect of denosumab on bone mineral density and biochemical markers of bone turnover: six-year results of a phase 2 clinical trial. J Clin Endocrinol Metab 96:394-402
20. McClung MR, Lewiecki EM, Geller ML, Bolognese MA, Peacock M, Weinstein RL, Ding B, Rockabrand E, Wagman RB, Miller PD (2013) Effect of denosumab on bone mineral density and biochemical markers of bone turnover: 8-year results of a phase 2 clinical trial. Osteoporos Int 24:227-235

21. Greenspan SL, Emkey RD, Bone HG, Weiss SR, Bell NH, Downs RW, McKeever C, Miller SS, Davidson M, Bolognese MA, Mulloy AL, Heyden N, Wu M, Kaur A, Lombardi A (2002) Significant differential effects of alendronate, estrogen, or combination therapy on the rate of bone loss after discontinuation of treatment of postmenopausal osteoporosis. A randomized, double-blind, placebocontrolled trial. Ann Intern Med 137:875-883

22. Wasnich RD, Bagger YZ, Hosking DJ, McClung MR, Wu M, Mantz AM, Yates JJ, Ross PD, Alexandersen P, Ravn P, Christiansen C, Santora AC, Early Postmenopausal Intervention Cohort Study Group (2004) Changes in bone density and turnover after alendronate or estrogen withdrawal. Menopause 11:622-630

23. Bone HG, Bolognese MA, Yuen CK, Kendler DL, Miller PD, Yang YC, Grazette L, San Martin J, Gallagher JC (2011) Effects of denosumab treatment and discontinuation on bone mineral density and bone turnover markers in postmenopausal women with low bone mass. J Clin Endocrinol Metab 96:972-980

24. Eisman JA, Bone HG, Hosking DJ, McClung MR, Reid IR, Rizzoli R, Resch H, Verbruggen N, Hustad CM, DaSilva C, Petrovic R, Santora AC, Ince BA, Lombardi A (2011) Odanacatib in the treatment of postmenopausal women with low bone mineral density: three-year continued therapy and resolution of effect. J Bone Miner Res 26:242-251

25. Ascott-Evans BH, Guanabens N, Kivinen S, Stuckey BG, Magaril $\mathrm{CH}$, Vandormael K, Stych B, Melton ME (2003) Alendronate prevents loss of bone density associated with discontinuation of hormone replacement therapy: a randomized controlled trial. Arch Intern Med 163:789-794

26. Black DM, Bilezikian JP, Ensrud KE, Greenspan SL, Palermo L, Hue T, Lang TF, McGowan JA, Rosen CJ, PaTH Study Investigators (2005) One year of alendronate after one year of parathyroid hormone (1-84) for osteoporosis. N Engl J Med 353:555-565

27. Freemantle N, Satram-Hoang S, Tang ET, Kaur P, Macarios D, Siddhanti S, Borenstein J, Kendler DL, DAPS Investigators (2012) Final results of the DAPS (Denosumab Adherence Preference Satisfaction) study: a 24-month, randomized, crossover comparison with alendronate in postmenopausal women. Osteoporos Int 23:317326

28. Boonen S, Ferrari S, Miller PD, Eriksen EF, Sambrook PN, Compston J, Reid IR, Vanderschueren D, Cosman F (2012) Postmenopausal osteoporosis treatment with antiresorptives: effects of discontinuation or long-term continuation on bone turnover and fracture risk - a perspective. J Bone Miner Res 27:963-974

29. Ivaska KK, Gerdhem P, Väänänen HK, Akesson K, Obrant KJ (2010) Bone turnover markers and prediction of fracture: a prospective follow-up study of 1040 elderly women for a mean of 9 years. $J$ Bone Miner Res 25:393-403

30. Brown JP, Roux C, Törring O, Ho PR, Beck Jensen JE, Gilchrist N, Recknor C, Austin M, Wang A, Grauer A, Wagman RB (2013) Discontinuation of denosumab and associated fracture incidence: analysis from the Fracture Reduction Evaluation of Denosumab in Osteoporosis Every 6 Months (FREEDOM) trial. J Bone Miner Res 28:746-752

31. Egerdie BR, Tammela T, Sieber P, Lamy O, Ke C, Warner D (2015) Denosumab treatment for bone loss in men receiving androgen deprivation therapy for nonmetastatic prostate cancer: 5-year safety follow-up. Can Urol Assoc J (CUA Annual Meeting Abstracts) 9(5-6 Suppl 2):S91

32. Anastasilakis AD, Makras P (2016) Multiple clinical vertebral fractures following denosumab discontinuation. Osteoporos Int 27: 1929-1930 
33. Aubry-Rozier B, Gonzalez-Rodriguez E, Stoll D, Lamy O (2016) Severe spontaneous vertebral fractures after denosumab discontinuation: three case reports. Osteoporos Int 27:1923-1925
34. Popp AW, Zysset PK, Lippuner K (2016) Rebound-associated vertebral fractures after discontinuation of denosumab-from clinic and biomechanics. Osteoporos Int 27:1917-1921

35. Black DM, Rosen CJ (2016) Postmenopausal osteoporosis. N Engl J Med 374:2096-2097 